\title{
Facilitated Beam-Walking Recovery during Acute Phase by Kynurenic Acid Treatment in a Rat Model of Photochemically Induced Thrombosis Causing Focal Cerebral Ischemia
}

\author{
Masahiro Abo ${ }^{a}$ Hideki Yamauchi $^{\mathrm{a}}$ Masahiko Suzuki ${ }^{\mathrm{b}}$ Mio Sakuma ${ }^{\mathrm{c}}$ \\ Mitsuyoshi Urashimac \\ a Department of Rehabilitation, ${ }^{b}$ Department of Neurology, and ${ }^{\mathrm{c} D i v i s i o n}$ of Clinical Research and Development, \\ The Jikei University School of Medicine, Tokyo, Japan
}

\section{Key Words}

Gene expression profiling $\cdot$ Cerebral ischemia $\cdot$ Animal model

\begin{abstract}
We previously demonstrated the presence of activated areas in the non-injured contralateral sensorimotor cortex in addition to the ipsilateral sensorimotor cortex of the area surrounding a brain infarction, using a rat model of focal photochemically induced thrombosis (PIT) and functional magnetic resonance imaging. Using this model, we next applied gene expression profiling to screen key molecules upregulated in the activated area. RNA was extracted from the ipsilateral and contralateral sensorimotor cortex to the focal brain infarction and from the sham controlled cortex, and hybridized to gene-expression profiling arrays containing 1,322 neurology-related genes. Results showed that glycine receptors were upregulated in both the ipsilateral and contralateral cortex to the focal ischemic lesion. To prove the preclinical significance of upregulated glycine receptors, kynurenic acid, an endogenous antagonist to glycine receptors on neuronal cells, was administered intrathecally. As a result, the kynurenic acid significantly improved behavioral
\end{abstract}

recovery within 10 days from paralysis induced by the focal PIT ( $p<0.0001)$, as evaluated with beam walking. These results suggest that intrathecal administration of a glycine receptor antagonist may facilitate behavioral recovery during the acute phase after brain infarction.

Copyright $\odot 2006$ S. Karger AG, Basel

\section{Introduction}

After cancer and heart disease, stroke is the third leading cause of death in most developed countries, including Japan. It is also a major cause of morbidity, long-term disability, hospital admissions, and healthcare costs [1]. The role of several neuroprotective agents in preventing the morbidity and mortality associated with stroke has been extensively tested in randomized clinical trials of acute ischemic stroke; however, no agent has proven effective, despite promising results in animal studies $[2,3]$. The driving theory behind these clinical trials is that excitotoxicity induced by high concentrations of extracellular glutamate and glycine in the brain after cerebral ischemia may further destroy neurons around the lesion by stimulating $N$-methyl-D-aspartate (NMDA) receptors [2]. As a

\section{KARGER}

Fax +4161306 1234 E-Mail karger@karger.ch www.karger.com
Mitsuyoshi Urashima, MD, PhD, MPH

Division of Clinical Research and Development, Jikei University School of Medicine 3-25-8 Nishi-shimbashi, Minato-ku

Tokyo 105-8461 (Japan)

Tel. +81 33433 1111/ext. 2405, Fax +81 35400 1250, E-Mail urashima@jikei.ac.jp 
result, research into the kinetics of excitatory amino acids in stroke and a search to develop novel drugs to antagonize NMDA receptors began [3]. However, NMDA antagonists (competitive receptor antagonists, iron channel blockers, and glycine antagonists) - including selfotel, aptiganel, eliprodil, licostinel, and gavestinel - failed to show efficacy in clinical trials of stroke or traumatic brain injury [4-7]. Some trials were even terminated because of increased mortality or psychotic effects in the active treatment group [8]. Although the disappointment associated with the failure of recent clinical trials is great, research into the mechanisms of neuro-reorganization or neuro-regeneration after brain infarction should be continued, as it is an extraordinary and important field.

The development of microarray methods for largescale analysis of gene expression made it possible to search systematically for key molecules involved in various diseases. We have applied this approach to the fields of oncology [9-11] and immunology [12]. In previous works on neurology, gene expression profiling was used in rodent models of transient middle cerebral artery occlusion $(\mathrm{MCAO})[13,14]$; results elucidated many genes associated with transient cerebral ischemia. However, behavioral recovery in the MCAO model may vary widely between individual rodents. Moreover, counteractions to these altered gene expressions, perhaps to improve neuromotor disability, have remained unproven; unfortunately, understanding these counteractions is a critical step that needs to be taken in translational research. To overcome this issue, we selected the rat model of brain infarction using photochemically induced thrombosis (PIT) by platelet aggregation [15]. The technique used in this model is simple and allows researchers to design a focal and uniform brain lesion; in addition, the hemiparesis of the hindlimb induced by the unilateral motor cortex recovers completely at 10 days with the least individual differences among rats after infarction $[16,17]$. By allowing us to develop permanent cortical lesions, which are relevant to clinical settings, this rat model lets us compare the effects of experimental treatments with sufficient sensitivity to detect minor differences between treatments through detailed evaluation of behavioral recovery after brain infarction.

Using the PIT model and functional magnetic resonance imaging (fMRI), we previously revealed the activated area in the non-injured contralateral sensorimotor cortex in addition to the ipsilateral sensorimotor cortex of infarction [18]. A similar phenomenon was observed in humans using fMRI $[19,20]$. Recently, adaptive functional changes in the human brain after focal damage have been examined [21, 22]. Therefore, we hypothesized that altered gene expressions involved in both the ipsilateral and contralateral cortex to the infarct lesion may contribute to functional neuro-reorganization of neural networks and modulate behavioral recovery after brain infarction. In contrast, altered gene expressions in only the ipsilateral cortex may be associated with reactions during wound healing that are not specific to neuro-reorganization. As a first step to screen key molecules associated with neuro-reorganization after brain infarction, gene expression profiles with GeneChip of ipsilateral specimens from around the infarct lesion were compared with those from the contralateral sensorimotor cortex as well as with control specimens, using the PIT model. Then, we intervened to counteract key molecules identified by GeneChip and observed differential speeds of behavioral recovery after infarction, using the PIT model.

\section{Materials and Methods}

\section{Animals}

The experiments described in the present study were carried out in accordance with the 'Guiding Principles for the Care and Use of Animals in the Field of Physiological Sciences' of the Physiological Society of Japan. In addition, this study was carried out in compliance with the institutional guidelines of animal experiments at Jikei University School of Medicine. A total of 40 female Fischer rats, aged 15 weeks, were used in this study. All rats were kept under standardized conditions (12-12 h light-dark cycle, lights on 7 a.m. and off 7 p.m., with free access to food and water), which were the same conditions used in our previous studies [17].

Because alterations of gene expressions were theoretically expected to occur before functional sensorimotor recovery, we sacrificed rats $48 \mathrm{~h}$ after injury. In contrast, 10 days were required to observe complete recovery of sensorimotor function represented by beam walking, as in our previous experiments [16-18]. Therefore, rats were separated into two groups for (1) RNA extraction $(\mathrm{n}=24)$ and (2) intervention and observation of beam walking $(\mathrm{n}=16)$.

\section{Photochemically Induced Thrombosis Model}

To prepare the PIT model, rats were anesthetized with isoflurane (induction $3.0 \%$ in air; maintenance $1.5 \%$ in air) and placed in a stereotaxic frame (Narishige, Tokyo, Japan). After cutting the skin and galea, a light beam $8 \mathrm{~mm}$ in diameter, with a $150 \mathrm{~W}$ cold-type halogen light (PICL-NEX, Japan), was focused on the skull and centered over the right hindlimb sensorimotor cortex at bregma $-1.0 \mathrm{~mm}, 2.0 \mathrm{~mm}$ lateral to the midline $[16,17]$. Aluminum foil tape was placed along the midline of the left side of the skull to avoid damage to the left side. The right femoral vein was exposed and cannulated using a needle attached to a microinjection pump. Rose Bengal, $80 \mathrm{mg} / \mathrm{kg}$ (dissolved in $0.9 \%$ saline), was infused at a rate of $60 \mu \mathrm{l} / \mathrm{min}$. Light exposure com- 
menced $90 \mathrm{~s}$ after the end of the infusion. The total light exposure time was $15 \mathrm{~min}$. Sham controlled rats were anesthetized and injected with Rose Bengal solution, the skin and galea were cut, and we waited $15 \mathrm{~min}$ but did not use any light exposure. Thus the only difference between intervention and control rats was the exposure to light.

\section{Behavioral Training and Testing}

The apparatus used for behavioral analysis consisted of two wooden beams, $200 \mathrm{~cm}$ long, 15 and $10 \mathrm{~mm}$ wide, supported by a U-shaped metal profile that functioned to prevent lateral vibration. The $15-\mathrm{mm}$ wide beam was used on the first day of training and was followed thereafter by the use of a $10-\mathrm{mm}$ wide beam. The beam was inclined $10^{\circ}$ and rigidly fixed at each end. The lower end of the beam was $40 \mathrm{~cm}$ above ground, and the upper end was flush with the top rim of the home cage. The middle section of the beam, a length of $122 \mathrm{~cm}$, was marked at the start and end points and designated as the test distance. After the lesion was induced, sensorimotor skills were evaluated daily for 13 days, using beam walking as a behavioral test with a 7-point nonparametric scale [23] for scoring impairment. No aversive stimuli or prompting was used. Scoring was solely made on the hindlimb contralateral to the brain lesion, as no effect on sensorimotor performance was observed on the ipsilateral hindlimb. The 90-second test session began when the rat could stay balanced on the beam without assistance. Behavioral response was scored using the following criteria. A score of 7 was given for no more than two hindlimb slips contralateral to the lesioned cortex. A score of 6 was given if the contralateral hindlimb was used for more than $50 \%$ of the test distance. A score of 5 was given if the limb was used for less than $50 \%$ of the test distance. A score of 4 was given if the animal was able to get the affected limb up on the surface of the beam but could not push off the surface without slipping. A score of 3 was given if the animal was able to traverse the test distance without using the affected limb, unable to get the affected limb up on the surface of the beam. A score of 2 was given if the animal could not traverse the test distance within $90 \mathrm{~s}$, but was able to stay balanced on the beam. A score of 1 was given if the animal fell off the beam. The session ended when the contralateral hindlimb passed the end point of the test distance, when $90 \mathrm{~s}$ had elapsed, or when the rat fell from the beam. The observer rating motor behavior was not informed whether active drug or placebo was used.

RNA Extraction and GeneChip Analysis

Forty-eight hours after infarction, rats were sacrificed to extract total RNA from the brain. A rectangular block $2 \mathrm{~mm}$ in the sagittal direction $\times 5 \mathrm{~mm}$ in the coronal direction $\times 3 \mathrm{~mm}$ deep was obtained from the right sensorimotor cortex excluding the infarct lesion and the same-size rectangular block was obtained from the left sensorimotor cortex of the injured rat. Similarly, same-size rectangular blocks were obtained from the left and right sensorimotor cortex of control rats.

A minimum $11 \mu \mathrm{g} / \mathrm{sample}$ of total RNA verified with spectrophotometric analysis $\left(\mathrm{OD}_{260 / 280}\right)$ was extracted with RNeasy (Qiagen Inc., Valencia, Calif., USA). Microarray expression analysis was performed according to the Affymetrix GeneChip Expression Analysis Manual. Briefly, RNA was converted to doublestranded cDNA (Gibco BRL Superscript Choice System; Life Technologies) and then to biotinylated cRNA (Bioarray High
Yield RNA Transcription Labeling Kit; Enzo Diagnostics, Farmingdale, N.Y., USA). After fragmentation and quality confirmation with the Affymetrix Test 2 Array, $7 \mu \mathrm{g}$ of the biotinylated cRNA was hybridized to an Affymetrix Rat Neurobiology U34 GeneChip oligonucleotide array containing 1,322 functional genes (Affymterix, Santa Clara, Calif., USA) for $16 \mathrm{~h}$ at $40^{\circ} \mathrm{C}$. The chip was washed twice. Hybridized biotinylated probes were stained with streptavidin-phycoerythrin and scanned with a probe array protocol.

\section{Intervention}

Kynurenic acid (Nacalai Tesque, Kyoto, Japan) was dissolved in phosphate-buffered saline (PBS) with $0.1 \%$ bovine serum albumin (BSA) at a concentration of $100 \mu \mathrm{mol} / \mathrm{l}$. Within $5 \mathrm{~min}$ after finishing exposure to the cold halogen light under anesthesia, kynurenic acid solution $(\mathrm{n}=8)$ or PBS with BSA alone $(50 \mu \mathrm{l})$ $(n=8)$ was injected in the left ventriculus lateralis (contralateral to the injury) at bregma $-1.0 \mathrm{~mm}, 2.0 \mathrm{~mm}$ lateral to the midline and $4.0 \mathrm{~mm}$ deep at a rate of $20 \mu \mathrm{l} / \mathrm{min}$ in rats using a 27-gauge needle. Then, beam walking was observed for 13 days.

\section{Statistics}

To eliminate changes within the range of background noise and to select variably expressed transcripts, data were used only if a p value of a random permutation test for each gene expression between the injured cortex (both ipsilateral and contralateral to the infarction) and the control cortex was $<0.05$ using STATA 8.0 (STATA Corp., College Station, Tex., USA). The distribution of maximum $t$ statistics based on 10,000 random permutations was compared with the observed values to determine the $\mathrm{p}$ value and its $95 \%$ confidence interval for each gene. Then, hierarchical clustering was performed with Spotfire software, version 8.0 (Spotfire, Somerville, Mass., USA). The Z score, that is, the standard deviation from the normal mean value of raw data transformed by $\log 2$ in each gene, was used for normalization.

The Kruskal-Wallis test was used to detect differences of each gene expression between the ipsilateral and contralateral cortex to the infarction and the control cortex with STATA 8.0. Permutation tests using the Mann-Whitney test were applied to confirm differential expression between the ipsilateral and contralateral cortex and between the contralateral and control cortex using STATA 8.0 (STATA Corp.). The effects of intervention compared with control on behavioral recovery were computed by repeated measure analysis of variance using STATA 8.0.

\section{Results}

\section{Gene Expression Profile}

First, we applied hierarchical clustering to classify all 21 samples, using the 112 most variably expressed transcripts. The resulting clusters showed distinctions between the injured side (right side), non-injured side (left side), and controls (fig. 1), although the right and left sides of the control brains were not differentiated statistically. 

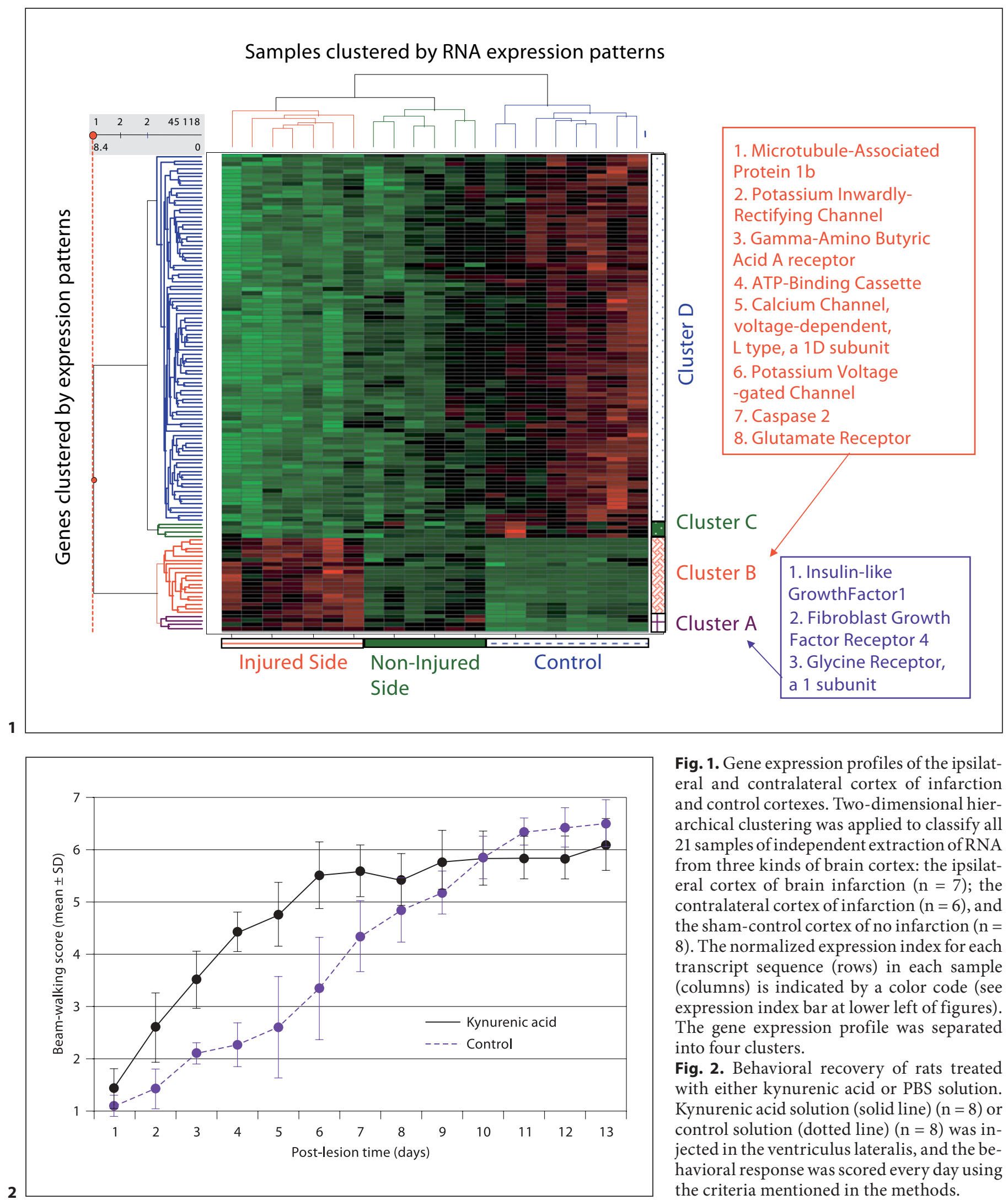

Fig. 1. Gene expression profiles of the ipsilateral and contralateral cortex of infarction and control cortexes. Two-dimensional hierarchical clustering was applied to classify all 21 samples of independent extraction of RNA from three kinds of brain cortex: the ipsilateral cortex of brain infarction $(n=7)$; the contralateral cortex of infarction $(n=6)$, and the sham-control cortex of no infarction $(\mathrm{n}=$ 8). The normalized expression index for each transcript sequence (rows) in each sample (columns) is indicated by a color code (see expression index bar at lower left of figures). The gene expression profile was separated into four clusters.

Fig. 2. Behavioral recovery of rats treated with either kynurenic acid or PBS solution. Kynurenic acid solution (solid line) $(n=8)$ or control solution (dotted line) $(\mathrm{n}=8)$ was injected in the ventriculus lateralis, and the behavioral response was scored every day using the criteria mentioned in the methods. 
Table 1A. List of genes in cluster $\mathrm{A}^{1}$ and fold changes of RNA expression levels in the ipsilateral and contralateral cortex compared with controls ${ }^{2}$

\begin{tabular}{|c|c|c|c|c|c|}
\hline Gene name & Symbol & $\begin{array}{l}\text { Ipsilateral/ } \\
\text { control }^{3}\end{array}$ & $\begin{array}{l}\text { Contralateral/ } \\
\text { control }^{4}\end{array}$ & $\begin{array}{l}\text { Ipsilateral/ } \\
\text { contralateral }^{5}\end{array}$ & $\begin{array}{l}\mathrm{p} \\
\text { value }^{6}\end{array}$ \\
\hline Insulin-like growth factor 1 & Igf1 & $14.4(0.0004)$ & $9.1(<0.0001)$ & 1.6 (NS) & 0.0001 \\
\hline Glycine receptor, $\alpha 1$-subunit & Glra1 & $4.0(<0.0001)$ & $3.7(<0.0001)$ & 1.1 (NS) & 0.0001 \\
\hline Fibroblast growth factor receptor 4 & Fgfr4 & $3.1(0.0005)$ & $2.6(0.0014)$ & 1.2 (NS) & 0.0003 \\
\hline Nitric oxide synthase 3 , endothelial cell & Nos3 & 1.5 & 0.9 & 1.6 & $<\times 2^{7}$ \\
\hline Voltage-gated channel-like 1 & Vgcnl1 & 1.1 & 1.1 & 1.0 & $<\times 2^{7}$ \\
\hline Synaptotagmin 4 & Syt4 & 1.0 & 0.9 & 1.2 & $<\times 2^{7}$ \\
\hline RAB28, member RAS oncogene family & Rab28 & 1.1 & 1.1 & 1.0 & $<\times 2^{7}$ \\
\hline Macrophage stimulating 1 (hepatocyte growth factor-like) & Mst1 & 1.2 & 1.1 & 1.0 & $<\times 2^{7}$ \\
\hline Potassium inwardly-rectifying channel & Kcnj2 & 1.3 & 1.2 & 1.1 & $<\times 2^{7}$ \\
\hline Met proto-oncogene & Met & 1.5 & 1.4 & 1.1 & $<\times 2^{7}$ \\
\hline Adrenergic receptor, $\alpha 1 \mathrm{D}$ & Adrald & 1.1 & 1.1 & 1.0 & $<\times 2^{7}$ \\
\hline
\end{tabular}

All data are given as fold change (in brackets: $\mathrm{p}$ value).

${ }^{1}$ Cluster $\mathrm{A}$ is defined in figure 1.

${ }^{2}$ Permutation tests using the Mann-Whitney test were applied to confirm differential expression between two of three parts: ipsilateral and contralateral cortex to the injured side as well as the cortex of control rats.

${ }^{3}$ Ipsilateral cortex of injured rats vs. the cortex of control rats.

${ }^{4}$ Contralateral cortex of injured rats vs. the cortex of control rats.

${ }^{5}$ Ipsilateral cortex vs. contralateral cortex of injured rats.

${ }^{6}$ The Kruskal-Wallis test was used to detect differences of gene expression among the ipsilateral and contralateral cortex to the infarction and the control cortex.

${ }^{7}$ Any amplitude of upregulation $<2$ was ignored and no statistical calculation was performed.

RNA expressions of three genes were upregulated in both the injured side and non-injured side at least twice as high as in the control cortex and were represented as clusterA:glycinereceptor, $\alpha 1$-subunit(GLRA1:Rn.10109); fibroblast growth factor receptor 4 (FGFR4: Rn.24104), and insulin-like growth factor 1 (IGF1: Rn.6282), which showed no differences in RNA expressions between the ipsilateral and contralateral cortex but was significantly upregulated compared with the control cortex (table 1A). In these three genes, expression of glycine receptors was equivalent between the injured and non-injured sides.

Cluster B represents genes expressed the most in the injured cortex, an intermediate amount in the non-injured cortex, and the least in the control cortex. In cluster $\mathrm{B}$, the following genes were upregulated at least twice as high as in both the ipsilateral and contralateral sides than in the control cortex: glutamate receptors, ionotropic, kainate 3; caspase 2; potassium voltage-gated channel, Isk-related subfamily, member 1; calcium channel, voltage-dependent, L-type, $\alpha 1 \mathrm{D}$-subunit, and $\gamma$-aminobutyric acid A receptor, $\alpha 5$, which showed significantly higher expressions in the ipsilateral cortex than in the contralateral cortex to the infarction (table 1B). Other genes depressed in both sides of the injured brain were classified as clusters C and D.

\section{Effect of Intervention on Motor Recovery}

We targeted glycine and glutamate receptors and intervened with kynurenic acid. Kynurenic acid is known as an endogenous glutamate receptor antagonist, displaying a particularly high affinity for the glycine site of NMDA receptors. Patterns of behavioral recovery after brain infarction evaluated with beam-walking ability were compared between rats administered kynurenic acid or PBS intrathecally (fig. 2). All rats had uniform severe neurologic impairment at day 1 . Recovery speed of rats treated with kynurenic acid was significantly more rapid than control rats $(\mathrm{p}<0.0001)$. However, after day 10 , motor recovery of control rats caught up and exceeded that seen in rats that received kynurenic acid, although differences between groups were not statistically significant. 
Table 1B. List of genes in cluster $\mathrm{B}^{1}$ and fold changes of RNA expression levels in the ipsilateral and contralateral cortex compared with controls ${ }^{2}$

\begin{tabular}{|c|c|c|c|c|c|}
\hline Gene name & Symbol & $\begin{array}{l}\text { Ipsilateral/ } \\
\text { control }^{3}\end{array}$ & $\begin{array}{l}\text { Contralateral/ } \\
\text { control }^{4}\end{array}$ & $\begin{array}{l}\text { Ipsilateral/ } \\
\text { contralateral }^{5}\end{array}$ & p value ${ }^{6}$ \\
\hline Caspase 2 & Casp2 & $39.9(0.0004)$ & $6.3(<0.0001)$ & $6.3(0.0014)$ & 0.0001 \\
\hline Glutamate receptor, ionotropic, kainate 3 & Grik3 & $11.7(0.0004)$ & $1.9(0.0026)$ & $6.2(0.0011)$ & 0.0001 \\
\hline Potassium inwardly-rectifying channel & Kcnj3 & $8.1(0.0004)$ & $2.8(<0.0001)$ & $2.9(0.0014)$ & 0.0001 \\
\hline ATP-binding cassette & Abcb6 & $6.0(0.0004)$ & $1.9(0.0002)$ & $3.2(0.0018)$ & 0.0001 \\
\hline Calcium channel, voltage-dependent, L-type, $\alpha 1 \mathrm{D}$ & Cacnald & $6.0(0.0004)$ & $1.9(0.0002)$ & $2.2(0.0012)$ & 0.0001 \\
\hline $\begin{array}{l}\text { Potassium voltage-gated channel, Isk-related subfamily, } \\
\text { member } 1\end{array}$ & Kcnel & $4.7(0.0004)$ & $1.8(<0.0001)$ & $2.6(0.0006)$ & 0.0001 \\
\hline Microtubule-associated protein $1 \mathrm{~b}$ & Map1b & $3.5(0.0004)$ & $1.9(<0.0001)$ & $1.8(0.0012)$ & 0.0001 \\
\hline$\gamma$-Aminobutyric acid A receptor, $\alpha 5$ & Gabra5 & $2.4(0.0004)$ & 1.4 & $1.7(0.0018)$ & 0.0004 \\
\hline Macrophage inflammatory protein-1 $\alpha$ receptor & LOC57301 & 1.8 & 1.5 & 1.2 & $<\times 2^{7}$ \\
\hline $\begin{array}{l}\text { Potassium intermediate/small conductance calcium- } \\
\text { activated channel, subfamily N, member } 3\end{array}$ & Kcnn3 & 3.5 & 1.0 & 3.6 & $\mathrm{NS}^{8}$ \\
\hline ATPase, $\mathrm{Na}^{+} \mathrm{K}^{+}$transporting, $\alpha 1$ & Atpla1 & 63.9 & 3.7 & 17.1 & $\mathrm{NS}^{8}$ \\
\hline Neurexophilin 4 & Nxph4 & 14.4 & 2.8 & 5.1 & $\mathrm{NS}^{8}$ \\
\hline Calpaimall subunit 1 & Cap1 & 12.2 & 2.9 & 4.3 & $\mathrm{NS}^{8}$ \\
\hline Inulin 1 & I1 & 2.0 & 1.3 & 1.6 & $\mathrm{NS}^{8}$ \\
\hline Survival motor neuron & Smn & 3.0 & 0.9 & 3.1 & $\mathrm{NS}^{8}$ \\
\hline Nerve growth factor receptor & Ngfr & 1.7 & 1.0 & 1.6 & $<\times 2^{7}$ \\
\hline Potassium voltage-gated channel & Kcne1 & 4.8 & 1.9 & 2.6 & $\mathrm{NS}^{8}$ \\
\hline Solute carrier family 6 , member 4 & Slc6a4 & 2.8 & 1.6 & 1.7 & $\mathrm{NS}^{8}$ \\
\hline p21 (CDKN1A)-activated kinase 1 & Pak1 & 1.5 & 1.1 & 1.3 & $<\times 2^{7}$ \\
\hline Chloride channel 5 & Clcn5 & 2.3 & 1.4 & 1.7 & $\mathrm{NS}^{8}$ \\
\hline Sodium channel, voltage-gated, type 8 & Scn8a & 3.4 & 1.7 & 2.1 & $\mathrm{NS}^{8}$ \\
\hline Hypocretin receptor 1 & Hcrtr1 & 2.2 & 1.4 & 1.6 & $\mathrm{NS}^{8}$ \\
\hline Citron & Cit & 2.2 & 1.3 & 1.7 & $\mathrm{NS}^{8}$ \\
\hline Calmodulin 1 & Calm1 & 1.8 & 1.2 & 1.5 & $<\times 2^{7}$ \\
\hline Calcium/calmodulin-dependent protein kinase IV & Camk4 & 33.0 & 1.6 & 20.2 & $\mathrm{NS}^{8}$ \\
\hline Brain-specific cortactin-binding protein CBP90 & Cbp90 & 23.7 & 3.5 & 6.7 & $\mathrm{NS}^{8}$ \\
\hline Neurofilament 3 , medium & Nef3 & 2.8 & 1.0 & 2.8 & $\mathrm{NS}^{8}$ \\
\hline Thyroid hormone receptor- $\alpha$ & Thra & 1.8 & 1.2 & 1.5 & $<\times 2^{7}$ \\
\hline $\begin{array}{l}\text { Potassium voltage-gated channel, shaker-related subfamily, } \\
\text { member } 6\end{array}$ & Kcna6 & 1.3 & 1.0 & 1.3 & $<\times 2^{7}$ \\
\hline Synaptosomal-associated protein, $23 \mathrm{kD}$ & Snap23 & 1.6 & 1.2 & 1.3 & $<\times 2^{7}$ \\
\hline Bassoon & Bsn & 2.1 & 1.3 & 1.5 & $\mathrm{NS}^{8}$ \\
\hline GABA-A receptor pi subunit & Gabrp & 1.6 & 1.1 & 1.5 & $<\times 2^{7}$ \\
\hline
\end{tabular}

\footnotetext{
${ }^{1}$ Cluster B is defined in figure 1.

2 Permutation tests using the Mann-Whitney test were applied to confirm differential expression between two of three parts: ipsilateral and contralateral cortex to the injured side as well as the cortex of control rats.

${ }^{3}$ Ipsilateral cortex of injured rats vs. the cortex of control rats.

${ }^{4}$ Contralateral cortex of injured rats vs. the cortex of control rats.

${ }^{5}$ Ipsilateral cortex vs. contralateral cortex of injured rats.

${ }^{6}$ The Kruskal-Wallis test was used to detect differences of gene expression among the ipsilateral and contralateral cortex to the infarction and the control cortex.

${ }^{7}$ Any amplitude of upregulation $<2$ was ignored and no statistical calculation was performed.

${ }^{8} \mathrm{NS}=$ Not significantly different evaluated.
} 


\section{Discussion}

In this study, RNA expressions of glycine receptors screened from 1,322 genes were upregulated in both the ipsilateral and contralateral cortex to the infarction compared with controls. Furthermore, using kynurenic acid as an antagonist for glycine/glutamate receptors, we have proved the functional importance of altered expressions of these receptors in the recovery process in the PIT model.

Gene expression profiles have been reported to be different between published articles [24, 25], which may be due to different target genes, different target lesions of the brain, different experimental designs, different timing of harvesting RNA, and variability of the experiments. We initially used a PIT model combined with the GeneChip screening system. However, since we focused only on the 1,322 neurology-related microarray genes, we might have missed important genes not included in the GeneChip that we used, which is the limitation of this experiment. Any amplitude of upregulation $<2$ was ignored, and a random permutation test was further applied to overcome the statistical issue of multiple testing [11]. Furthermore, genes for which RNA expressions were downregulated in the infarction group were not used in this study. Because caspase, which is related to apoptosis, was upregulated up to 40 -fold in the ipsilateral cortex of the infarction compared with controls, it suggests that neuronal cells around the infarction were already dying. Therefore, we tried to avoid this secondary and non-specific downregulation of gene expressions induced during the cellular dying process.

Recently, blockades of both glycine and glutamate receptors were demonstrated to require an inhibiting NMDA receptor [26, 27], implying that antagonists against either the glycine or glutamate receptors may not be sufficient to block NMDA receptors. In fact, all clinical trials using either an antagonist for glycine receptors or glutamate receptors failed to show an improved prognosis for patients after brain infarction or injury [2]. On the other hand, kynurenic acid, as the only known endogenous antagonist, may block both glycine and glutamate receptors in NMDA receptors [25]. In addition, kynurenic acid non-competitively inhibits release of glutamate by acting on nicotinic acetylcholine presynaptic receptors [28]. Moreover, in the neonatal rat model, asphyxia raises levels of kynurenic acid transiently at birth [29] and reduces hypoxic damage in brain tissue $[30,31]$. Therefore, we selected kynurenic acid as an inhibitor for NMDA receptors to confirm the findings of upregulated RNA expressions of NMDA receptors.
At day 1, all rats had uniform severe neurologic impairment with or without kynurenic acid treatment. Then, kynurenic acid significantly improved the speed of behavioral recovery after infarction, as expected. However, after day 10, motor recovery of control rats caught up. This finding suggests that the effect of kynurenic acid may facilitate recovery rather than neuroprotection, since if kynurenic acid had neuroprotective effects, neurologic impairment at day 1 would have been lighter in the kynurenic acid group than in the control group. Additional experiments using delayed administration of kynurenic acid are required to discriminate between these two assumptions.

In previous literature, hyperexcitation of NMDA has been shown to mediate glutamate-induced cell death [32, 33]. However, NMDA receptors are also critically involved in cognitive function [34], modulation of neuronal migration [35], and synapse development [36] as well as anti-apoptotic actions in the developing brain [37]. Although blockades of NMDA and its signaling were demonstrated to have neuroprotective effects in rodent models in a number of neurons or areas of ischemic damage [38], no reports compared behavioral recovery, as was done in this study. Using a permanent MCAO stroke model in the rat, the potent glycine antagonist 7-chlorothiokynurenic acid was found to be effective in attenuating infarct size, which was not behavioral recovery [39]. However, behavioral recovery is used to evaluate outcomes of other agents in terms of neuroprotective effects after brain injury [40]. In this experiment, kynurenic acid was administrated intrathecally immediately after infarction. However, this treatment is not always feasible in general clinical settings of patients with stroke. Thus, in future studies, we are planning to evaluate the effects of intravenous administration of kynurenic acid on behavioral recovery and compare different doses and different timing of administration using the PIT model. Moreover, established models have been adapted to different species and used for functional and behavioral testing [41].

In addition to altered expressions of glycine and glutamate receptors, fibroblast growth factor receptor and insulin growth factor were upregulated not only in the ipsilateral but also in the contralateral cortex to the infarction side. Although associated evidence has been reported in previous literature [42-44], discussion about these molecules is beyond the scope of this paper, as altered expressions of these molecules have not been confirmed by other approaches.
Abo/Yamauchi/Suzuki/Sakuma/ Urashima 
In conclusion, glycine receptors were screened from 1,322 genes with GeneChip analysis, and kynurenic acid, an endogenous antagonist for glycine receptors, facilitated behavioral recovery during the acute phase in the PIT model.

\section{Acknowledgment}

This study was supported by a Japanese Grant in Aid for Scientific Research.

\section{References}

1 Yoneda Y, Uehara T, Yamasaki H, Kita Y, Tabuchi M, Mori E: Hospital-based study of the care and cost of acute ischemic stroke in Japan. Stroke 2003;34:718-724.

2 Ikonomidou C, Turski L: Why did NMDA receptor antagonists fail clinical trials for stroke and traumatic brain injury? Lancet Neurol 2002;1:383-386.

3 Olverman HJ, Jones AW, Watkins JC: L-Glutamate has higher affinity than other amino acids for $\left[{ }^{3} \mathrm{H}\right]$-D-AP5 binding sites in rat brain membranes. Nature 1984;307:460462.

4 Morris GF, Bullock R, Marshall SB, Marmarou A, Mass A, Marshall LF: Failure of the competitive $N$-methyl-D-aspartate antagonist Selfotel (CGS 19755) in the treatment of severe head injury: results of two phase III clinical trials. J Neurosurg 1999;91:737-743.

5 Albers GW, Clark WM, Atkinson RP, Madden K, Data JL, Whitehouse MJ: Dose escalation study of the NMDA glycine-site antagonist licostinel in acute ischemic stroke. Stroke 1999;30:508-513.

-6 Albers GW, Goldstein LB, Hall D, Lesko LM: Aptiganel hydrochloride in acute ischemic stroke: a randomized controlled trial. JAMA 2001;286:2673-2682.

-7 Sacco RL, DeRosa JT, Haley EC, Levin B, Ordronneau P, Phillips SJ, Rundek T, Snipes RG, Thompson JLP: Glycine antagonist in neuroprotection for patients with acute stroke. JAMA 2001;285:1719-1728.

-8 Davis SM, Albers GW, Diener HC, Lees KR, Norris J: Termination of acute stroke studies involving sefotel treatment. Lancet 1997; 349:32.

-9 Ishibashi Y, Hanyu N, Nakada K, Suzuki Y, Yamamoto T, Yanaga K, Ohkawa K, Hashimoto N, Nakajima T, Saito H, Matsushima M, Urashima M: Profiling gene expression ratios of paired cancerous and normal tissue predicts relapse of esophageal squamous cell carcinoma. Cancer Res 2003;63:5159-5164.

10 Yuza Y, Agawa M, Matsuzaki M, Yamada H, Urashima M: Gene and protein expression profiling during differentiation of neuroblastoma cells triggered by 13 -cis retinoic acid. J Pediatr Hematol Oncol 2003;25:715720.
11 Okamoto A, Nikaido T, Ochiai K, Takakura S, Saito M, Aoki Y, Ishii N, Yanaihara N, Yamada K, Takikawa O, Kawaguchi R, Isonishi S, Tanaka T, Urashima M: Indoleamine 2,3-dioxygenase serves as a marker of poor prognosis in gene expression profiles of serous ovarian cancer cells. Clin Cancer Res 2005; 11:6030-6039.

12 Urashima M, Sakuma M, Teramoto S, Fuyama Y, Eto Y, Kondo K, Tanaka T: Gene expression profiles of peripheral and cord blood mononuclear cells altered by thymic stromal lymphopoietin. Pediatr Res 2005;57: 563-569.

13 Lu XCM, Williams AJ, Yao C, Berti R, Hartings JA, Whipple R, Vahey MT, Polavarapu RG, Woller KL, Tortella FC, Dave JR: Microarray analysis of acute delayed gene expression profile in rats after focal ischemic brain injury and reperfusion. J Neurosci Res 2004; 77:843-857.

14 Sugahara-Kobayashi M, Takahashi Y, Nagata T, Nishida Y, Murata A, Ishikawa K, Asai $S$ : Screening for control genes in rat global cerebral ischemia using high-density oligonucleotide array. J Neurosci Res 2004;76: 512-518.

15 Watson BD, Dietrich WD, Busto R, Wachtel MS, Ginsberg MD: Induction of reproducible brain infarction by photochemically initiated thrombosis. Ann Neurol 1985;17:497504.

16 Abo M, Yamauchi H, Chen Z, Yonemoto K, Miyano S, Bjelke B: Behavioural recovery correlated with MRI in a rat experimental stroke model. Brain Injury 2003;17:799808.

17 Abo M, Miyano S, Eun SS, Yamauchi H: Histochemical characterization of skeletal muscles in rats with photochemically-induced stroke. Brain Injury 2004;18:1017-1024.

18 Abo M, Chen Z, Lai LJ, et al: Functional recovery after brain lesion-contralateral neuro-modulation: an fMRI study. Neuroreport 2001;12:1543-1547.

19 Kim YH, Jang SH, Chang Y, Byun WM, Son S, Ahn SH: Bilateral primary sensori-motor cortex activation of post-stroke mirror movements: an fMRI study. Neuroreport 2003;14:1329-1332.

-20 Cao Y, D’Olhaberriague L, Vikingstad EM, Levine SR, Welch KMA: Pilot study of functional MRI to assess cerebral activation of motor function after poststroke hemiparasis. Stroke 1998;29:112-122.
21 Ward NS: Neural plasticity and recovery of function. Prog Brain Res 2005;150:527-535.

22 Calautti C, Baron JC: Functional neuroimaging studies of motor recovery after stroke in adults: a review. Stroke 2003;34:15531566.

23 Feeney DM, Gonzalez A, Law WA: Amphetamine, haloperidol, and experience interact to affect rate of recovery after motor cortex injury. Science 1982;217:855-857.

24 Hayashi T, Noshita N, Sugawara T, Chan PH: Temporal profile of angiogenesis and expression of related genes in the brain after ischemia. J Cereb Blood Flow Metab 2003; 23:166-180.

25 Tang Y, Nee AC, Lu A, Ran R, Sharp FR: Blood genomic expression profile for neuronal injury. J Cereb Blood Flow Metab 2003; 23:310-319.

26 Nong Y, Huang YQ, Ju W, Kalia LV, Ahmadian G, Wang YT, Salter MW: Glycine binding primes NMDA receptor internalization. $\mathrm{Na}-$ ture 2003;422:302-307.

27 Furukawa H, Gouaux E: Mechanisms of activation, inhibition and specificity: crystal structures of the NMDR receptor NR1 ligand-binding core. EMBO J 2003;22:28732885.

28 Nemeth H, Toldi J, Vecsei L: Role of kynurenines in the central and peripheral nervous systems. Curr Neurovasc Res 2005;2: 249-260.

29 Ceresoli-Borroni G, Schwarcz R: Neonatal asphyxia in rats: acute effects on cerebral kynurenine metabolism. Pediatric Res 2001; 50:231-235.

-30 Andine P, Lehmann A, Ellren K, Wennberg E, Kjellmer I, Nielsen T, Hagberg H: The excitatory amino acid antagonist kynurenic acid administered after hypoxic ischemia in neonatal rats offers neuroprotection. Neurosci Lett 1988;90:208-212.

-31 Nozaki K, Beal MF: Neuroprotective effects of L-kynurenine on hypoxia-ischemia and NMDA lesions in neonatal rats. J Cereb Blood Flow Metab 1992;12:400-407.

- 32 Simon RP, Swan JH, Griffiths T, Meldrum BS: Blockade of $N$-methyl-D-aspartate receptors may protect against ischemic damage in the brain. Science 1984;226:850-852

33 Faden AI, Demediuk P, Panter SS, Vink R: The role of excitatory amino acids and NMDA receptors in traumatic brain injury. Science 1989;244:798-800. 
-34 Malenka RC, Nicoll RA: Long-term potentiation - a decade of progress? Science 1999; 285:1870-1874.

-35 Scheetz AJ, Constantine-Paton M: Modulation of NMDA receptor function: implications for vertebrate neural development. FASEB J 1994;8:745-752.

-36 Komuro H, Rakic P: Modulation of neuronal migration by NMDA receptors. Science 1993;260:95-97.

\37 Ikonomidou C, Bosch F, Mikasa M, et al: Blockade of NMDA receptors and apoptotic neurodegeneration in the developing brain. Science 1999;283:70-74.
38 Aarts M, Liu Y, Liu L, Besshoh S, Arundline M, Gurd JW, Wang YT, Salter MW, Tymianski M: Treatment of ischemic brain damage by perturbing NMDA receptor-PSD-95 protein interactions. Science 2002;298:846850.

39 Chen J, Graham S, Moroni F, Simon R: A study of the dose dependency of a glycine receptor antagonist in focal ischemia. J Pharmacol Exp Ther 1993;267:937-941.

40 Kundrotiene J, Wagner A, Liljequist S: Extradural compression of sensorimotor cortex: a useful model for studies on ischemic brain damage and neuroprotection. J Neurotrauma 2002;19:69-84.

-41 Northington FJ: Brief update on animal models of hypoxic-ischemic encephalopathy and neonatal stroke. ILAR J 2006;47:32-38.
42 Yoshimura S, Takagi Y, Harada J, Teramoto T, Thomas SS, Waeber C, Bakowska JC, Breakefield XO, Moskowitz MA: FGF-2 regulation of neurogenesis in adult hippocampus after brain injury. Proc Natl Acad Sci USA 2001;98:5874-5879.

43 Schabitz WR, Hoffmann TT, Heiland S, Kollmar R, Bardutzky J, Sommer C, Schwab $S$ : Delayed neuroprotective effect of insulinlike growth factor-I after experimental transient focal cerebral ischemia monitored with MRI. Stroke 2001;32:1226-1233.

44 Lopez-Lopez C, LeRoith D, Torres-Aleman I: Insulin-like growth factor I is required for vessel remodeling in the adult brain. Proc Natl Acad Sci USA 2004;101:9833-9838. 